\title{
Chronic widespread pain in the population: a seven year follow up study
}

\author{
A C Papageorgiou, A J Silman, G J Macfarlane
}

Ann Rheum Dis 2002;61:1071-1074

See end of article for authors' affiliations

....................

Correspondence to: Professor Gary J Macfarlane, The Unit of Chronic Disease

Epidemiology, School of Epidemiology and Health Sciences, The Medical

School, The University of Manchester, Oxford Road, Manchester M13 9PT, UK:

G.Macfarlane@man.ac.uk

Accepted 26 April 2002

\begin{abstract}
Objectives: To document the natural course of chronic widespread pain (CWP) in a general population sample over a seven year period and to identify comorbidities which predict persistence.

Methods: A mailed survey questionnaire returned by 2334 adults registered with two general practices was used to obtain information on pain status (no pain, regional pain, or CWP) and other health and pain symptoms. Seven years later a second questionnaire was sent to responders who were still registered with the same general practice, asking about their current pain status.

Results: Information was obtained for 1386 adults (an adjusted response of $93 \%$ ). The prevalence of CWP was similar for both surveys at $11 \%$ and $10 \%$ respectively. Of those with CWP initially, a third recorded CWP on the second survey and $15 \%$ were pain free. Only $2 \%$ of subjects with no initial pain had developed CWP at follow up. Of subjects with CWP on the initial survey who were aged over 50 years and reported dry eyes or mouth and daytime tiredness, 77\% reported CWP seven years later. This contrasts with a persistence of only $9 \%$ for those aged under 50 and with neither symptom recorded at initial survey.

Conclusion: The proportion of subjects from a general population sample changing from CWP to no pain, or vice versa, over a seven year period was very low. This suggests that pain, once established, is likely to persist (or recur) especially if accompanied by other somatic symptoms and older age.
\end{abstract}

\section{METHODS}

In 1991 a survey questionnaire was sent to 2034 people registered with a large general practice in rural Cheshire. Adults aged between 20 and 85 years were randomly selected from within age and sex stratified groups, with a higher proportion selected for inclusion from the younger age groups. The next year the same questionnaire was mailed to a further 2161 adults similarly selected from the register of a second Cheshire practice in a more urban setting.

The seven page survey questionnaire requested demographic details and included eight questions about musculoskeletal aches and pains in the past month (see appendix A). A further 10 questions on other health symptoms were selected from the Fatigue Questionnaire,$^{10}$ the Somatic Symptoms Checklist, ${ }^{11}$ and the General Health Questionnaire (see appendix B). ${ }^{12}{ }^{13}$ Current pain status was established by asking if, during the past month, the person had experienced an ache or pain which had lasted for one day or longer. Those responding positively were asked whether or not the pain had been present for more than three months, and directed to shade in the site of the ache or pain on a blank body manikin. Further questions asked if the pain was still present and whether their general practitioner had been consulted because of the pain.

The survey questionnaire was returned by 2334 subjects, a response rate of $75 \%$ after adjustment for persons not living at the registered address. Information from the shaded manikin on the sites and spread of pain, and from the question on pain duration permitted responders with CWP (defined according to the definition of the American College of Rheumatology used in the criteria for fibromyalgia) to be identified. Subjects with pain who did not meet the definition of CWP were classified as having regional pain. A subset of 141 subjects had been studied previously to determine outcome at two years. ${ }^{6}$

In 1997 attempts were made to identify on the practice lists 2105 subjects, born in or after 1916, who had responded to the initial 1991-2 survey questionnaires. It was decided not to include the 229 subjects born before 1916 as they might have problems completing the questionnaire. A total of 1588 (75\%)

Abbreviations: $\mathrm{Cl}$, confidence interval; $\mathrm{CWP}$, chronic widespread pain; OR, odds ratio 


\begin{tabular}{|c|c|c|c|c|}
\hline & \multicolumn{3}{|c|}{ Pain group on 1998 survey } & \multirow[b]{2}{*}{$\begin{array}{l}1991 \\
\text { Totals }\end{array}$} \\
\hline & $\begin{array}{l}\text { CWP } \\
\text { n (\%) }\end{array}$ & $\begin{array}{l}\text { Other pain } \\
\mathrm{n}(\%)\end{array}$ & $\begin{array}{l}\text { No pain } \\
\mathrm{n}(\%)\end{array}$ & \\
\hline \multicolumn{5}{|c|}{ Pain group on 1991 survey: } \\
\hline CWP & $59(34.1)$ & $89(51.4)$ & 25 (14.5) & 173 \\
\hline Other pain & $62(10.4)$ & $330(55.6)$ & 202 (34.0) & 594 \\
\hline No pain & $13(2.3)$ & $193(34.3)$ & 356 (63.3) & 562 \\
\hline 1998 Totals & 134 & 612 & 583 & $1329 *$ \\
\hline
\end{tabular}

* 57 of 1386 subjects $(4 \%)$ were not categorised owing to missing data.

subjects who responded to the original survey were identified as still registered with the same practice and these comprised the follow up cohort. Of the remaining 517 subjects, 120 were identified by the Office for National Statistics as having died during the follow up period. Over an 18 month period from early 1998 the 1588 subjects identified were sent a further survey questionnaire. As with the original 1991-2 survey, this included a blank manikin and identical questions on the site and duration of pain; the pain and health symptom questions (detailed in the appendices) were not included. Nonresponders were sent a postcard reminder and then a further questionnaire. Those still not responding were sent a shortened version of the questionnaire and, if necessary, contacted by telephone. The addresses of subjects for whom a response was still not received were then checked against the electoral register to identify those who were no longer living at the address registered with the general practice.

\section{Analysis}

The categories of pain at the two periods were compared using simple cross tabulations. Prognostic factors for subjects with
CWP in 1991-2 were identified using logistic regression and expressed as odd ratios (ORs), with $95 \%$ confidence intervals (95\% CIs) adjusted for age and sex. The outcome variable was whether or not CWP was indicated on the 1998 follow up survey questionnaire.

All variables identified as having a significant OR by univariate analysis were presented as candidates for entry into a forward stepwise logistic regression model to identify a small group of independent factors predicting outcome at seven years.

\section{RESULTS}

\section{Response rates and loss to follow up}

Of the 1588 subjects mailed at follow up, 1386 questionnaires $(87 \%)$ were returned after up to three reminders. When the addresses of the 202 non-responders were checked against the electoral register, almost half (97) were found not to live at their listed address, making an adjusted response rate of $93 \%$.

\section{The natural course of CWP over seven years}

Table 1 shows the changes in pain status over the seven year follow up period. A third (59) of the 173 adults with CWP in 1991 still met the criteria seven years later, $51 \%$ had "other pain", and only $15 \%$ were free of pain. By comparison $2 \%$ and $10 \%$ of subjects with no pain and "other pain" at baseline had developed CWP after seven years, respectively. Similar results were found when data for men and women were examined separately.

\section{Predictors of long term outcome of CWP}

To examine factors which might predict the persistence of CWP, only the 173 subjects reporting CWP on the original survey are considered. Sex did not influence the seven year outcome, with men and women equally likely to report persistent pain. However, subjects over 50 years of age were three times more likely to have persistent symptoms than subjects younger than 50 years (table 2).

\begin{tabular}{|c|c|c|c|}
\hline \multirow[b]{2}{*}{ Exposure in 1991} & \multicolumn{3}{|c|}{ Outcome in 1998} \\
\hline & $\begin{array}{l}\text { No CWP } \\
\text { (controls 114) }\end{array}$ & $\begin{array}{l}\text { CWP } \\
\text { (cases 59) }\end{array}$ & $\begin{array}{l}\text { Adjusted for sex/age* } \\
\text { OR }(95 \% \mathrm{CI})\end{array}$ \\
\hline \multicolumn{4}{|l|}{ Sex: $†$} \\
\hline Women & 81 & 40 & 1.0 \\
\hline Men & 33 & 19 & $0.9(0.4$ to 1.7$)$ \\
\hline \multicolumn{4}{|l|}{ Age: $\dagger$} \\
\hline$\leqslant 50$ years & 52 & 13 & 1.0 \\
\hline$>50$ years & 62 & 46 & $3.0(1.4$ to 6.1$)$ \\
\hline \multicolumn{4}{|l|}{ Pain characteristic: } \\
\hline Current pain & 85 & 53 & $2.5(0.9$ to 6.7$)$ \\
\hline Consulted general practitioner with pain & 72 & 46 & $2.1(0.9$ to 4.5$)$ \\
\hline \multicolumn{4}{|l|}{ Pain statements: } \\
\hline Ache all over & 19 & 20 & $2.4(1.1$ to 5.4$)$ \\
\hline Awake in night & 41 & 37 & $2.4(1.2$ to 4.8$)$ \\
\hline Pain in muscles & 61 & 34 & $1.1(0.6$ to 2.3$)$ \\
\hline Ache in morning & 74 & 47 & $1.8(0.8$ to 4.4$)$ \\
\hline Neck and shoulder pain & 86 & 50 & $1.6(0.6$ to 4.1$)$ \\
\hline Stiff in morning & 77 & 49 & $1.4(0.6$ to 3.5$)$ \\
\hline Pain in back & 98 & 51 & $0.7(0.2$ to 1.9$)$ \\
\hline Joint pains & 81 & 46 & $0.96(0.4$ to 2.6$)$ \\
\hline \multicolumn{4}{|l|}{ Health symptoms: } \\
\hline Worn out & 72 & 25 & $1.8(0.9$ to 3.6$)$ \\
\hline Too tired & 20 & 26 & $4.8(2.2$ to 10.8$)$ \\
\hline Joints swollen & 21 & 15 & $1.6(0.7$ to 3.5$)$ \\
\hline Numbness & 13 & 10 & $1.7(0.7$ to 4.5$)$ \\
\hline Bowel problems & 17 & 13 & $1.8(0.8$ to 4.4$)$ \\
\hline Dry eyes/mouth & 15 & 20 & 3.5 (1.5 to 7.9$)$ \\
\hline Fingers white & 16 & 12 & $1.8(0.8$ to 4.4$)$ \\
\hline Lost sleep & 25 & 15 & $1.3(0.6$ to 2.8$)$ \\
\hline Difficulties & 20 & 16 & $1.8(0.8$ to 3.9$)$ \\
\hline Feeling depressed & 29 & 19 & $1.6(0.8$ to 3.3$)$ \\
\hline
\end{tabular}


Table 3 In those with CWP in 1991, the forward stepwise logistic regression model identified three factors* predicting persistent CWP

\begin{tabular}{llc}
\hline \multirow{2}{*}{$\begin{array}{l}\text { Number of } \\
\text { exposures in model }\end{array}$} & \multicolumn{2}{l}{ Outcome: CWP in 1998} \\
\cline { 2 - 3 } $\begin{array}{l}\text { No CWP } \\
\mathrm{n}(\%)\end{array}$ & $\begin{array}{c}\text { CWP } \\
\mathrm{n}(\%)\end{array}$ \\
\hline 0 & $40(91)$ & $4(9)$ \\
1 & $50(64)$ & $28(36)$ \\
2 & $18(51)$ & $17(49)$ \\
3 & $3(23)$ & $10(77)$ \\
\hline
\end{tabular}

*Too tired during the day, aged over 50 years, dry mouth/eyes.

Of the eight pain statements (detailed in appendix A), subjects who reported "I ache all over" or "pain keeps me awake at night" were twice as likely to experience persistent CWP as those not thus affected in 1991-2. Of the 10 health symptoms (listed in appendix B) only being "too tired during the day" and having "dry eyes or dry mouth" were significant risks for persistent pain (table 2). The three General Health Questionnaire questions, either individually or in combination, were not significantly associated with persistent pain.

Forward stepwise logistic regression modelling identified three factors which explained the persistence of CWP: "feeling too tired during the day to do what you want to do", aged over 50 years, and experiencing dry eyes or mouth (table 3 ). Of the 44 subjects with CWP at baseline who reported none of these factors, only four (9\%) still had CWP seven years later. However, 10 out of $13(77 \%)$ of subjects with CWP at baseline and responding positively to all three factors on the original survey questionnaire reported CWP on the follow up survey.

\section{DISCUSSION}

Subjects with CWP who were over 50 years of age and reported somatic symptoms and daytime tiredness were most likely to report CWP seven years later. Even if pain was present in the three months before the two occasions when the survey questionnaire was completed it cannot be assumed to have been present throughout the seven intervening years nor, inversely, absent in subjects free of pain on both occasions. However, the relatively few cases moving between the CWP group and the pain free group suggests that some subjects generally experienced more pain ( CWP or regional pain) whereas others had less pain (no pain or regional pain) during this period. Further, the ability to predict the persistence of CWP does suggest that these subjects' experience was distinct during the follow up period.

Only a limited number of health symptom questions were asked in the initial survey questionnaire. Although the rationale of abstracting three questions from the General Health Questionnaire could be argued, the decision to do so was based on a report that showed the three included questions to be good predictors of potential depression in the community. ${ }^{13}$ The remaining health symptoms were those found to be associated with fibromyalgia in studies undertaken before the initial 1990 survey - for example, those of Campbell et al. ${ }^{14}$ However, it has been argued that, given the range of personal experiences and characteristics, and the social, economic, and cultural factors that influence pain perception, any study hoping to shed light on the causes or persistence of CWP should investigate all these areas for potential risk factors. ${ }^{15} 16$ Subsequent community studies examining predictors of onset and persistence of fibromyalgia have shown the importance of factors such as illness behaviour, and (with more thorough evaluation than was available in this study) psychological distress, somatic symptoms, and fatigue. $^{89}$ Measurement of these factors is likely to have improved predictive ability in the current study.
The response rate to the initial survey was $75 \%$. Information obtained on non-responders did not differ substantially from that of subjects responding to the survey. ${ }^{1}$ The study has several strengths. As over $5 \%$ of the population is estimated to change their general practitioner each year, ${ }^{17}$ the high proportion $(75 \%)$ of the original survey participants included in the follow up study would suggest a fairly static study population. Almost a quarter of the subjects who were not identified for follow up had died in the seven years since the initial survey. The remaining subjects (presumed to have moved from the area) were similar to those included in the follow up cohort in terms of pain status, although younger women were overrepresented (data not shown). As the adjusted response to the follow up survey was high (93\%), it is unlikely that any significant non-response bias had occurred, particularly in relation to predictors of outcome.

The prevalence rates found in the current study are similar to those reported for other population surveys of CWP. ${ }^{2} 1819$ The prevalence of CWP was similar in both the initial ${ }^{1}$ and follow up surveys (at $11 \%$ and $10 \%$ respectively), although these figures disguise the fact that almost half of the subjects (44\%) had changed pain status over the seven year period. Although a few other studies have examined factors which predict CWP over seven or more years, ${ }^{20}{ }^{21}$ only one has reported specifically on the change in pain status over a similar period. In a study of pain in women Forseth et $a l^{4}$ documented an increase in CWP from $27 \%$ to $38 \%$ over five years due to regional and multifocal pain developing into CWP. We have previously proposed a more stringent definition (Manchester definition) for chronic widespread pain $^{22}$ with a correspondingly lower prevalence (about $4 \%$ ) in the community. ${ }^{23}$ In the current study, however, those meeting the Manchester criteria at baseline were no more likely to report CWP on follow up than those with CWP who did not meet the Manchester definition (data not shown).

In the current study, older age and two items from the "health symptoms" list (concerning dry eyes/mouth and day time tiredness) were independently associated with persistent CWP. Older age has been previously identified as a risk for persistent pain over a shorter time period, ${ }^{9}$ but not over a comparable follow up period..$^{21}$ Although the recording of dry eyes and dry mouth may suggest Sjögren's syndrome, a previous study has shown that their report was not related to other features of Sjögren's syndrome. ${ }^{24}$ The large differences in outcome depending on age and the presence of these two comorbidities does offer primary care physicians a few simple items that can distinguish groups at very different risks of persistent symptoms, with the prospect of targeting early management at those at high risk of persistence.

Considering the current study together with our two previous reports on the persistence of $\mathrm{CWP}^{69}$ these show a persistence of CWP of $56 \%$ at one year, $35 \%$ at two years, and $34 \%$ at seven years. Although, of course, persons with persistent pain may not be the same at each time point, the results suggest that, at worst, one third of patients will have persistent (although not necessarily continuous) pain in the long term. This can be predicted by older age and the presence of other somatic symptoms. In comparison with clinic based studies (where patients are likely to have more severe symptoms) the persistence rate is somewhat lower but still suggests an important long term burden.

\section{ACKNOWLEDGEMENTS}

This study was funded by the Arthritis Research Campaign (ARC), Chesterfield, UK. We thank the doctors and staff at Bollington Medical Centre and Wilmslow Road Surgery, Handforth, for their help with this study. We are grateful for the assistance of staff at National Statistics, Southport. Thanks also go to Rita Boswell and other staff at the ARC, past and present, who assisted with the conduct of the original studies. 


\section{APPENDIX A: PAIN STATEMENTS}

Here are some statements about pain. Please think back over the past month and tick one box for every statement. Tick the YES box for any which closely fit your experiences during the past month. Tick the NO box for those which do not apply.

I ache all over

Pain wakes me during the night

I have pain in my muscles

I ache when I wake up in the morning

I have pain in my neck and shoulders

I feel stiff when I get out of bed in the morning

I have pain in my back

I have pain in my joints

\section{APPENDIX B: OTHER HEALTH SYMPTOMS}

Here are some questions about other health matters. Please tick one box for every questions, choosing the one which most closely fits your recent experience. We would like to know how you have been feeling during the past month.

Do you ever wake up after your usual amount of sleep feeling tired and worn out?*

Do you feel too tired during the day to do what you want to do?*

Do your joints ever feel swollen?†

Do your arms or legs ever feel numb? $\dagger$

Do you suffer from constipation or diarrhoea? $\dagger$

Do your eyes or mouth feel dry? $†$

Do your fingers become white and painful in the cold weather?†

Have you recently lost much sleep over worry?ł

Have you recently felt you couldn't overcome your difficulties? $\neq$

Have you recently been feeling unhappy or depressed?‡

Responses were on a four point Likert scale.*questions from the Fatigue Questionnaire ${ }^{10}$; tquestions from the Somatic Symptoms Checklist $^{11}$; ‡questions from the General Health Questionnaire ${ }^{12}$

\section{Authors' affiliations}

A C Papageorgiou, A J Silman, G J Macfarlane, Arthritis Research Campaign Epidemiology Unit, School of Epidemiology and Health Sciences, The Medical School, The University of Manchester, Oxford Road, Manchester M13 9PT, UK

G J Macfarlane, The Unit of Chronic Disease Epidemiology, School of Epidemiology and Health Sciences, The Medical School, The University of Manchester, Oxford Road, Manchester M13 9PT, UK

\section{REFERENCES}

1 Croft P, Rigby AS, Boswell R, Schollum J, Silman A. The prevalence of chronic widespread pain in the general population. J Rheumato 1993:20:710-13.
2 Wolfe F, Ross K, Anderson J, Russell IJ, Hebert L. The prevalence and characteristics of fibromyalgia in the general population. Arthritis Rheum 1995;38:19-28.

3 Croft P, Burt J, Schollum J, Thomas E, Macfarlane G, Silman A. More pain, more tender points: is fibromyalgia just one end of a continuous spectrum? Ann Rheum Dis 1996;55:482-5.

4 Forseth FO, Forre O, Gran JT. A 5.5 year prospective study of self reported musculoskeletal pain and of fibromyalgia in a female population: significance and natural history. Clin Rheumatol 1999:18:114-21.

5 Magni G, Caldieron C, Rigatti-Luchini S, Merskey H. Chronic musculoskeletal pain and depressive symptoms in the general population. An analysis of the 1 st national health and nutrition examination survey data. Pain 1990;43:299-307.

6 Macfarlane GJ, Thomas E, Papageorgiou AC, Schollum J, Croft PR, Silman AJ. The natural history of chronic pain in the community: a better prognosis than in the clinic? J Rheumatol 1996;23:1617-20.

7 McBeth J, Silman AJ. Unravelling the association between chronic widespread pain and psychological distress; an epidemiological approach [editorial]. J Psychosom Res 1999;47:109-14.

8 McBeth J, Macfarlane GJ, Benjamin S, Silman AJ. Features of somatization predict the onset of chronic widespread pain. Results of a large population based study. Arthritis Rheum 2001:44:940-6.

9 McBeth J, Macfarlane GJ, Hunt IM, Silman AJ. Risk factors for persistent chronic widespread pain: a community based study. Rheumatology 2001:40:95-101.

10 Chalder T, Berelowitz G, Pawlikowska T, Watts L, Wessely S, Wright D, et al. Development of a fatigue scale. J Psychosom Med 1993:37: 147-53.

11 Othmer E, DeSouza C. A screening test for somatisation disorder (hysteria). Am J Psychiatry 1985; 142:1146-9.

12 Goldberg DP, Williams P. A user's guide to the general health questionnaire. Windsor: NEFR-Nelson, 1988.

13 Hansen V, Jacobsen BK. Mental distress and social conditions and lifestyle in northern Norway. BM 1989;299:85-8.

14 Campbell SM, Clark S, Tindall EA. Forehand ME, Bennett RM. Clinical characteristics of fibrositis. 1. A "blinded" control study of symptoms and tender points. Arthritis Rheum 1983;26:817-24.

15 Andersson HI, Ejlertsson G, Leden I, Rosenberg C. Characteristics of subjects with chronic pain, in relation to local and widespread pain report. Scand J Rheumatol 1996;25:146-54

16 Carette S. Chronic pain syndromes. Ann Rheum Dis 1996;55:497-501.

17 Social Services. Transfer of medical records. BM 1978;ii:1493.

18 Macfarlane GJ, Morris S, Hunt IM, Benjamin S, McBeth J, Papageorgiou AC, et al. Chronic widespread pain in the community: the influence of psychological symptoms and mental disorder on healthcare seeking behavior. J Rheumatol 1999;26:413-9.

19 Crook J, Rideout E, Browne G. The prevalence of pain complaints in a general population. Pain 1984;18:299-314.

20 Hotopf M, Mayou R, Wadsworth M, Wessely S. Temporal relationship between physical symptoms and psychiatric disorder. Br J Psychiatry 1998; 173:255-61

21 Magni G, Moreschi C, Rigatti-Luchini S, Merskey H. Prospective study on the relationship between depressive symptoms and chronic musculoskeletal pain. Pain 1994;56:289-97.

22 Macfarlane GJ, Croft PR, Schollum J, Silman AJ. Widespread pain: is an improved classification possible? J Rheumatol 1996;23:1628-32.

23 Hunt IM, Silman AJ, Benjamin S, McBeth J, Macfarlane GJ. The prevalence and associated features of chronic widespread pain in the community using the "Manchester" definition of chronic widespread pain. Rheumatology 1999;38:275-9.

24 Hay EM, Thomas E, Pal B, Hajeer A, Chambers H, Silman AJ. Weak association between subjective symptoms and objective testing for dry eyes and dry mouth: results from a population based study. Ann Rheum Dis 1998;57:20-2.. 